\title{
A War of (Mis)Information: The Political Effects of Rumors and Rumor Rebuttals in an Authoritarian Country
}

\author{
HAIFENG HUANG*
}

Despite the prevalence of anti-government rumors in authoritarian countries, little is currently known about their effects on citizens' attitudes toward the government, and whether the authorities can effectively combat rumors. With an experimental procedure embedded in two surveys about Chinese internet users' information exposure, this study finds that rumors decrease citizens' trust in the government and support of the regime. Moreover, individuals from diverse socio-economic and political backgrounds are similarly susceptible to thinly evidenced rumors. Rebuttals generally reduce people's belief in the specific content of rumors, but often do not recover political trust unless the government brings forth solid and vivid evidence to back its refutation or win the endorsement of public figures broadly perceived to be independent. But because such high-quality and strong rebuttals are hard to come by, rumors will erode political support in an authoritarian state. These findings have rich implications for studies of rumors and misinformation in general, and authoritarian information politics in particular.

Rumors as unsubstantiated information ${ }^{1}$ exist in almost every society, but can be particularly prevalent in authoritarian countries due to their restrictions on independent news media. This is because they usually emerge and spread amid social uncertainty and anxiety, ${ }^{2}$ which are exacerbated by the lack of credible public information from free media. ${ }^{3}$ While rumors can also be detrimental in a democracy and reverberate for a long time among users of fringe information sources, ${ }^{4}$ they can be even more destructive to authoritarian governments, since rumors in a non-democracy are an alternative form of media that directly competes with official information and mainstream media, and therefore constitutes a counter-power against official power. ${ }^{5}$ The 1989 social protests that brought regime change in the former Czechoslovakia, for example, started with a false rumor that a university student had been brutally killed by the police. ${ }^{6}$ During the Tiananmen movement that same year in China, as well as many local riots in more recent times, rumors also played a critical role in mobilizing the participants. ${ }^{7}$

* Assistant Professor of Political Science, University of California, Merced (e-mail: hhuang24@ucmerced. edu). I am grateful to Steve Nicholson, Tom Hansford, Evan Heit, Xiaobo Lu, Brendan Nyhan, Danie Stockmann, Yao-Yuan Yeh, and four anonymous reviewers for detailed and valuable comments. Brett Benson, Terry Nichols Clark, Rick Dales, Matt Hibbing, Pierre Landry, Peter Lorentzen, Anne Meng, Mike Munger, Mehdi Shadmehr, Susan Shirk, Jiangnan Zhu and audiences at MPSA, Duke University (Political Science), UC Berkeley (Center for Chinese Studies) and UC San Diego (IR/PS) have also offered helpful suggestions on previous versions of the article. Data replication sets are available at https://dataverse.harvard.edu/dataverse/ BJPolS, and online appendices are available at http://dx.doi.org/doi:10.1017/S0007123415000253.

1 A more precise definition will be given in the 'Rumors, Rebuttals and Political Trust' section.

2 DiFonzo and Bordia 2007.

3 Kapferer 1990.

4 Mocanu et al. 2014.

5 Kapferer 1990.

6 Bilefsky 2009.

7 Pei 2008; Zhao 2001. 
While such cases indicate that rumors can spark or intensify social protests, little is currently known about their effects on public opinion in an authoritarian country during non-crisis times, and whether the government can effectively combat the informational counter-power. Since social crises are rooted in tensions accumulated during 'normal' times, understanding how battles over everyday, routine rumors accusing the government of various kinds of wrongdoings influence mass political attitudes will shed important light on the political dynamics in authoritarian countries, particularly regarding how citizens process competing information.

Social scientific studies of rumors have mostly been confined to social psychology and business research. The lack of political studies of rumors in authoritarian countries is particularly striking given their ubiquity and political significance. Managing information and news is a fundamental characteristic of authoritarianism, but despite the fact that information flows in authoritarian countries are multi-directional, the existing literature on information transmission in non-democracies focuses on the government's control of information and molding of public opinion through the propagation of pro-regime messages, ${ }^{8}$ the government's interaction with media ${ }^{9}$ or downright censorship. ${ }^{10}$ Anti-government information originating from the society has been far less studied. In particular, while government propaganda as inaccurate, exaggerated or purely fabricated claims and myths that favor the regime has received a great deal of scholarly attention, anti-government rumors as unverified and sometimes false information have largely been relegated to anecdotes rather than rigorous investigation, even though they are akin to (often unorganized) societal propaganda against the state. ${ }^{11}$

This study takes a first step toward filling this void by embedding an experimental procedure in two surveys about internet users' past information exposure in China, where rumors often go viral and the authorities are hard-pressed to contain them. While existing research on rumors and misinformation focuses on individuals' acceptance or rejection of their specific content, this article analyzes not only people's belief in rumors, but more importantly how rumors and rebuttals influence their trust in the government on larger policy issues related to the rumors and their support of the regime as a whole.

Although rumors can circulate via various means of communication, I focus on internet rumors because the internet, and especially social media (for example, microblogging), have dramatically increased the ease, speed and extent of rumor propagation. As a result, online rumors have been increasingly supplanting word-of-mouth rumor transmission. ${ }^{12}$ Despite the presence of censorship, the internet has become the most dynamic, contentious, and even chaotic battleground for information and ideas in China, ${ }^{13}$ and social media-based rumors feature prominently in the war over information in the country. By studying a significant form of microblogging-based information flow, this article is one of the first quantitative studies of the politics of social media in China, ${ }^{14}$ and hence improves our understanding of the political challenges the internet poses to an authoritarian government.

The study finds that rumors reduce citizens' trust in and support of the government, whether in terms of specific policy issues related to the rumors or the political system as a whole.

${ }^{8}$ E.g., Huang 2015; Kenez 1985; Wedeen 1999.

9 E.g., Shirk 2010; Stockmann 2013.

10 E.g., Egorov, Guriev, and Sonin 2009; Lorentzen 2014.

11 Previous studies have examined the effects of self-reported exposure to general rumor networks but not concrete rumors (Bauer and Gleicher 1953; Zhu, Lu, and Shi 2013).

12 Fine and Ellis 2010.

13 King, Pan, and Roberts 2013; Tong and Lei 2013.

14 Two other major quantitative political studies of Chinese social media are by King, Pan, and Roberts (2013, 2014), who focus on censorship rather than information competition. 
In addition, people's beliefs in rumors are not significantly affected by their socio-economic, demographic or even political backgrounds. Rebuttals of rumors, on the other hand, can reduce people's belief in their specific content, although a fair amount of belief in the rumors remains after the rebuttals. More importantly, typical rebuttals in the form of somewhat simple or perfunctory denials from (quasi-)official sources do not improve citizens' trust in the government that was damaged by the rumors. The evidence also suggests, however, that a wellevidenced rebuttal that offers a persuasive alternative characterization, or a rebuttal from a public figure widely viewed as independent of the government, will be more effective in recovering political trust and support.

Citizens in an authoritarian country, in other words, are broadly susceptible to thinly evidenced anti-government rumors, but they can also be persuaded by the authorities if the latter can bring forth powerful evidence to support their story or win the endorsement of public figures widely perceived to be independent. But to the extent that the government can only reduce (not eliminate) belief in rumors, and that strong or independent rebuttals are often difficult to come by given factors such as the inherent ambiguity of most rumors, it is hard for the government to win in this war of (mis)information. Ultimately, unless the underlying political and socio-economic issues are somehow addressed, rumors will erode political support in an authoritarian state.

\section{SOCIAL MEDIA AND THE BATTLE OVER RUMORS IN CHINA}

The internet has undergone rapid growth in China (which has more than 649 million users ${ }^{15}$ more than any other country in the world), and the social media and networking landscape is particularly vibrant. Weibo (www.weibo.com), a very popular microblogging platform with 129 million monthly active users and 45 million daily active users, ${ }^{16}$ stands out as the most influential social media site and the undisputed first source of real-time information in China. ${ }^{17}$ The rumors and rebuttals used in this study were all taken from Weibo.

Like Twitter, Weibo lets users post short messages (tweets) consisting of up to 140 characters that are automatically broadcast to the poster's followers, but it also has three other important features. First, Weibo posts can directly include pictures and videos (which do not count toward the post's character limit) in addition to text and links. Secondly, when forwarding (retweeting) another user's post, Weibo users can quote the original post in its entirety, including any picture or video it may contain, and add comments (the original post does not count toward the 140-character limit). Thirdly, Weibo allows nested dialogues: in addition to replying to or retweeting another user's post, Weibo users can choose to add comments and/or interact with other users directly under that post.

Such features make Weibo a Chinese Twitter with a Facebook look and feel. Together with the succinctness of the Chinese language, they also allow a Weibo post to contain considerably richer content than a Twitter post, while preserving the latter's brevity: ${ }^{18}$ two conditions that are ideal for the transmission of short but vivid stories such as rumors. Conversations on Weibo are thus often more vibrant than those on Twitter, and retweeting is more prevalent. ${ }^{19}$ It has been

15 CNNIC 2015.

16 'Weibo' means microblogging in Chinese, and the platform was previously known as 'Sina Weibo', reflecting its corporate ownership. The user data were from Weibo's initial public offering filing in 2014 (http:// www.sec.gov/Archives/edgar/data/1595761/000119312514100237/d652805df1.htm\#toc).

${ }^{17} \mathrm{Ng} 2013$.

18 The Economist 2012.

19 Yu, Asur, and Huberman 2011. 
widely regarded as the closest thing to a (huge) town square in China, where discussions of issues ranging from politics to entertainment can be unprecedentedly freewheeling. ${ }^{20}$ Unsurprisingly, Weibo's structure and vitality have also made it a fertile ground for rumors, including the high-profile and unusual rumor in 2012 following the sacking of Bo Xilai, an ambitious Political Bureau member of the Chinese Communist Party (CCP), that there was a coup staged by Bo's allies. ${ }^{21}$ Some statistics suggest that each day there is at least one rumor widely circulating on Weibo. ${ }^{22}$ Weibo has thus been dubbed 'the world's best rumor mongering machine ever' by Western media. ${ }^{23}$

The Chinese government has been greatly worried about online rumors. Besides periodic public warnings issued in the state media, top officials have personally visited the Sina Corporation, which owns Weibo, to admonish them about 'fake and harmful information' on Weibo. ${ }^{24}$ Weibo and some other Chinese websites have also been 'severely reprimanded' by the government for failures to control rumors. ${ }^{25}$ For instance, it was forced to suspend its comment function for three days following the coup rumor. Weibo has consequently established a points-based account management system, by which a user's credit points will be reduced for behaviors deemed improper, in particular that of 'spreading untrue information', ultimately leading to the closure of their account. ${ }^{26}$ The Chinese government has recently stepped up its struggle against rumors and launched an aggressive anti-rumor campaign, accusing or detaining a number of influential opinion leaders and active internet users for rumor mongering, and even issuing a legal interpretation that threatens social media users with defamation charges and possible prison terms if the rumors they produce are viewed more than 5,000 times or forwarded more than 500 times. $^{27}$

While unwelcome content on the internet can be censored and the most conspicuous producers can be penalized, the nature of social media means that an anti-government post may have already been read and forwarded by many internet users, thus entering public awareness and circulation (both online and offline), before it can be detected and deleted. Routine rumors also typically do not contain politically sensitive keywords, but mundane phrases and sentences, and thus cannot be filtered out by keywords-based systems before they are posted online. ${ }^{28}$ Online conversations are also vast, decentralized and constantly evolving, and so it is extremely difficult to stamp out every piece of offensive content in every corner. In fact, criticisms of the government (including virulent ones) are prevalent on Chinese internet; ${ }^{29}$ Weibo has even become a platform of 'counter-hegemony' against official hegemony in Chinese political discourses. ${ }^{30}$ Rumors are close to criticism, in that they essentially accuse the government of certain wrongdoings. Therefore, rebuttals have been a critical part of the Chinese authorities'

20 Richburg 2011.

21 Epstein 2012; MacKinnon 2012.

22 Yang et al. 2012.

23 Larson 2011, 2012. Rumors also circulate on 'Wechat', a popular mobile internet application built around instant messaging that allows cell phone users to share text, audio, photos and video messages with individuals or small groups of mutual 'friends', which has led to official crackdowns such as the recent regulation that all Wechat public accounts need to be registered with real names (Levin 2014). The structure of Wechat, however, makes it much more conducive to private communication and sharing than open and public discussions.

$24 \mathrm{Ji}$ and Wang 2011.

25 Xinhua News Agency 2012.

26 Wines 2012.

27 Chin and Mozur 2013.

28 Chinese social media users also commonly convert texts into picture files and then post the pictures instead of the original texts, which makes the keywords-based censoring mechanism even harder to work.

29 King, Pan, and Roberts 2013.

30 Tong and Lei 2013; Yang 2013. 
struggle against rumors, in addition to censorship and the most recent crackdown. ${ }^{31}$ In addition to examining the effects of rumor rebuttals, this study will also illuminate the Chinese government's motivation behind the recent and ongoing aggressive crackdown on 'rumor mongering'.

Weibo maintains a dedicated rumor rebuttal account, @WeiboPiyao (Weibo Rumor Rebuttals), which is staffed by senior journalists twenty-four hours a day and regularly issues rebuttals. ${ }^{32}$ While technically speaking these rebuttals are issued by the Weibo Corporation (or its parent company, Sina) rather than the government, they are often treated by internet users as quasi-official, because the firm's management enjoys a close relationship with the Chinese government, which is widely regarded as the reason that Weibo has been allowed to grow and thrive while an earlier popular microblogging site named Fanfou was shut down following ethnic unrest in 2009. Editors of the rebuttal account also regularly contact government agencies and official media organizations for verification of information. Since the introduction of the points-based reputation system, Weibo has added another rumor control account, @WeiboGuanliyuan (Weibo Administrator), which periodically announces penalties to Weibo users for forging or spreading 'fake information' and sometimes rebuts rumors directly. In the absence of an official centralized rumor rebuttal agency in China, Weibo's official anti-rumor accounts have taken on this role to some extent. ${ }^{33}$ To examine the effects of different types of rebuttals, those used in the first experiment of the study were taken from Weibo's official rumor rebuttal account, while in the second experiment I used a detailed rebuttal from a police department and another from a well-known public figure, both issued on Weibo.

Since the most common type of politically relevant internet rumors in China are about government malfeasance or negligence rather than political dramas such as coups, the rumors I study belong to the former category. Given the prevalence of such rumors in China, this ensures that the treatments would not be unusual to the subjects, and that the results indicate the real effects of rumors and rebuttals in the daily social lives of an authoritarian country.

\section{RUMORS, REBUTTALS AND POLITICAL TRUST}

What we currently know about rumors comes mostly from psychological and sociological studies. Therefore I follow the definition of rumor in the social psychology literature that has become more or less standard since Allport and Postman's classic study: ${ }^{34}$ a specific proposition for belief circulating in a society despite its lack of secure standards of evidence. The emphasis here is on the lack of evidence rather than falsehood, although some rumors on the Chinese internet can be readily shown to be false. Operationally speaking, the rumors selected for this study are claims circulating in society about specific events or situations that are supposed to have happened or existed, without sufficient evidence showing the claims to be true. The claims have also been refuted by official sources or public figures with at least some authority over the relevant matters. This practical selection criterion is close to Kapferer's definition of rumor as unofficial information 'that is either not yet publicly confirmed by official sources or denied by them'. ${ }^{35}$

\footnotetext{
31 For similar reasons, the Chinese government has encouraged its agencies and departments at various levels to set up Weibo accounts in order to 'emanate great voices at crucial moments' (People's Daily Online Media Opinion Monitoring Office 2012, 2), rather than having internet users drowned in unofficial information.

32 Cao and An 2011.

33 In August 2013, one year after the study's survey experiments, six Chinese websites launched a joint rumor-busting website for the Beijing area (http://py.qianlong.com/), the targets of which include not only social rumors but also (mis)beliefs about non-social matters such as personal health.

34 Allport and Postman (1947).

35 Kapferer (1990, 13).
} 
While the psychological, sociological and business literatures have studied a variety of rumors - including those during wartime, ${ }^{36}$ behind racial tensions, ${ }^{37}$ in the marketplace ${ }^{38}$ and about perceived threats across national borders ${ }^{39}$ - they primarily deal with the cognitive processes and social dynamics of rumor transmission rather than their political effects, which is the focus of the present study. The recently emerging interest in political science on misinformation, conspiracy theories and fact checking is similarly focused on factors such as political orientations, personality traits and social positions that affect belief in the specific content of false claims (as well as the best methods for correcting or stopping misinformation) ${ }^{40}$ rather than their effects on political attitudes. Nevertheless, this existing literature is a useful starting point for formulating hypotheses about the political effects of rumors and rebuttals in an authoritarian country. The political science literature on framing, which studies the public opinion consequences of alternative characterizations of issues, also offers helpful guidelines. In particular, in terms of attitudinal impacts, rumors versus rebuttals are analogous to one-sided versus two-sided framing, even though rumors and rebuttals focus on factual information rather than conceptual characterization, as is typically the case in framing. ${ }^{41}$

The first hypothesis of the article is about the effects of rumors. The existing research on rumors and misinformation is largely confined to democratic societies, where the existence of prevailing regime norms and independent news media means that rumors usually cannot directly compete with mainstream or official information. Instead, public opinion is heavily influenced by official and elite discourses. ${ }^{42}$ An authoritarian country, by contrast, lacks both (1) institutionalized democratic channels for interest aggregation and (2) independent and trustworthy news media for information transmission. This reduces the legitimacy and authority of official positions and messages, and lends more credibility to rumors as a form of counterinformation and counter-power. Since politically relevant rumors in an authoritarian country typically portray the government negatively, in the absence of rebuttals, the one-sided information flow from rumors will negatively affect citizens' attitudes toward the government. This is akin to the common finding in the framing literature that conceptualizing an issue in a certain direction or emphasizing some considerations over others will shift citizens' attitudes on the relevant issue more in line with those directions and considerations. ${ }^{43}$ The study's first hypothesis, therefore, is that rumors will reduce people's trust in and support of the government (Hypothesis 1).

Yet will rebuttals reduce people's belief in the rumors? The social psychology literature on rebuttals has focused on this question, and the results are somewhat mixed. The literature has identified a variety of rebuttal practices that are effective in many contexts, ${ }^{44}$ although some studies have also shown that corrections of misinformation can fail and may sometimes even backfire, ${ }^{45}$ especially when the content of a rebuttal directly challenges a person's world view or cultural identity. ${ }^{46}$ Since routine, everyday rumors in an authoritarian country are typically

${ }^{36}$ Allport and Postman 1947.

${ }^{37}$ Fine and Turner 2001; Knopf 1975.

${ }^{38}$ Kapferer 1990; Koller 1992.

${ }^{39}$ Fine and Ellis 2010.

${ }^{40}$ E.g., Berinsky 2012; Nyhan and Reifler 2010, forthcoming; Oliver and Wood 2014; Uscinski and Parent 2014.

${ }^{41}$ Druckman and Bolsen 2011.

${ }^{42}$ Zaller 1992.

${ }^{43}$ For a review of the literature, see Chong and Druckman (2007b).

${ }^{44}$ See DiFonzo and Bordia (2007, ch. 9) and Nyhan and Reifler (2012) for a review.

${ }^{45}$ Mayo, Schul, and Burnstein 2004; Schwarz et al. 2007.

${ }^{46}$ Cook and Lewandowsky 2011; Nyhan and Reifler 2010. 
about relatively mundane problems and do not by themselves directly constitute fundamental political issues, rebuttals as alternative framings can be expected to decrease, though not eliminate, recipients' belief in their specific content (Hypothesis 2). A rebuttal will often not completely eliminate belief in a rumor, because to do so the rebuttal needs to be able to conclusively invalidate the claims of a rumor, which is difficult for inherently ambiguous situations, and all recipients have to be fully attentive to the rebuttal.

A perhaps more important (but hitherto neglected) question about rebuttals is whether they can recover citizens' trust in the government that was damaged by the rumors; here the situation is more subtle. Although rumors are about specific events or situations, the stories usually have broader political or policy implications. As the existing social psychology literature has shown, rumors typically arise in environments of social stress, conflicts and information ambiguity, and therefore reflect people's anxieties, fear and resentment. For example, rumors about specific events that lead to racial conflicts usually crystallize hostile beliefs between different races, ${ }^{47}$ and those about foreign people and countries underscore a society's anxiety about perceived international threats. ${ }^{48}$ As such, rumors often serve as symbolic and warning tales for the believers regardless of the veracity of the specific 'facts' they allege. ${ }^{49}$ This is particularly the case in authoritarian countries, where government policies and practices are often distrusted. To the extent that believers focus more on the underlying message or 'moral' of a story rather than the specifics of a rumor, the effects of rebuttals on their belief in the content of a rumor and their trust of the government in relevant policy or political issues can be divergent. In particular, the effects of rebuttals on one's political trust may crucially hinge on the character and attributes of the rebuttals.

The literature on framing has shown that, with two-sided political communication, public opinion toward an issue will depend on the relative strength of the competing messages. ${ }^{50}$ The social psychology literature on rumors and misinformation has analogous findings. It shows that people's false beliefs about an issue or a person often have lasting effects on their attitudes and inferences, even when the misinformation is discredited. ${ }^{51}$ At the same time, if a correction is forceful and of high quality, the lingering effect of the initial misinformation will be limited. The relative power of the competing information against a rumor is the strength of the rebuttal. Therefore one can expect that a weak rebuttal will fail to recover people's trust in the government, even though it can reduce their belief in the specific content of a rumor, but a strong rebuttal will be more effective in recovering political trust.

This article focuses on two factors that have been identified in the social psychology and political behavior literatures to be significant in contributing to a message's strength and persuasiveness: the quality and source of a message. The first factor is easy to understand. In research on correcting misinformation, it has been shown that relatively simple or perfunctory negations in the form of ' $\mathrm{A}$ did not do $\mathrm{X}$ ' are not very effective, and may even reinforce the familiarity (and hence acceptability) of the original claim. ${ }^{52}$ On the other hand, responses to false claims that are vivid, well evidenced, and provide an alternative mental model for understanding the rumored event or situation will work considerably better. ${ }^{53}$

${ }^{47}$ Knopf 1975.

48 Fine and Ellis 2010.

49 Donovan 2007; Kapferer 1990.

50 Chong and Druckman 2007a, 2007c; Druckman, Peterson, and Slothuus 2013; cf. Sniderman and Theriault 2004.

${ }^{51}$ Ecker, Lewandowsky, and Tang 2010; Johnson and Seifert 1994; Ross, Lepper, and Hubbard 1975.

${ }_{52}$ Koller 1992; Mayo, Schul, and Burnstein 2004.

53 Johnson and Seifert 1994; Ross, Lepper, and Hubbard 1975. 
Research in public opinion has also long shown that citizens often take cues from the sources of messages when forming opinions about the messages,${ }^{54}$ especially when the relevant issues are complicated and ambiguous. ${ }^{55}$ In particular, messages from communicators who take a position that is unexpected by the audience will be better received. ${ }^{56}$ Formal theoretical work has further demonstrated that information from a source with a known bias might be particularly valuable to a decision maker. ${ }^{57}$ Thus when rebutting a rumor, which by definition is usually about an ambiguous situation, statements from sources that are perceived to be credible, especially public figures whose political positions are known to be different from the target of the rumors, will be more persuasive. ${ }^{58}$

A rebuttal that is strong in either message quality or source credibility can therefore be regarded as a strong rebuttal, and so the above discussion leads to the following related hypotheses: (1) rebuttals in the form of simple or perfunctory denials and from sources lacking a broad reputation of being independent of the government will not be effective in improving people's trust in the government that was previously damaged by rumors (Hypothesis 3a) and (2) rebuttals that offer vivid evidence and forceful explanation, and/or are from a source that is widely perceived to be independent from (and even critical of) the government can improve citizens' political trust that was previously damaged by rumors (Hypothesis 3b). Note that the improvement of political trust in Hypothesis 3 is relative to the rumor condition, because if a rebuttal can recover (some of) citizens' trust in the government that was previously weakened by a rumor, it can be regarded as at least somewhat successful. Whether a rebuttal can improve citizens' political trust above the control (pre-rumor) condition is an empirical question; it depends on a number of factors such as the specific strength of a rebuttal (for example, whether it provides an extra argument or information in addition to neutralizing the rumor).

These hypotheses do not mean, however, that an authoritarian government can combat rumors by simply producing high-quality rebuttals or having independent and well-known figures refute them. With regards to the quality of the rebuttal, most rumors are about situations that are inherently ambiguous and therefore hard to conclusively disprove, especially via statements in the media. And having independent public figures refute rumors will only be effective if they rarely speak in favor of the government. Therefore strong rebuttals are not always available to the government, the implications of which will be discussed in the concluding section.

\section{THE SURVEY EXPERIMENTS}

\section{Design and Recruitment}

Design. The study uses data from two online surveys conducted in spring-summer of 2012 about Chinese internet users' social opinion and past information exposure. Two rumors from the Chinese internet, denoted as A and B, and their associated rebuttals were embedded in each survey. Participants in each survey were randomly assigned to one of five groups that differed from each other in the questions they received about the rumors and rebuttals: (1) control group (no rumors or rebuttals); (2) rumors group; (3) rumors plus rebuttal A group; (4) rumors plus

54 Druckman 2003; Goren, Federico, and Kittilson 2009; Kuklinski and Hurley 1994; Lupia 1994; Mondak 1993; Nicholson 2012; Nicholson and Hansford 2014.

55 Cf. Nicholson 2011 .

56 Nicholson 2011; O'Keefe 2002, ch. 8.

57 Calvert 1985.

58 Berinsky 2012; DiFonzo and Bordia 2007. 


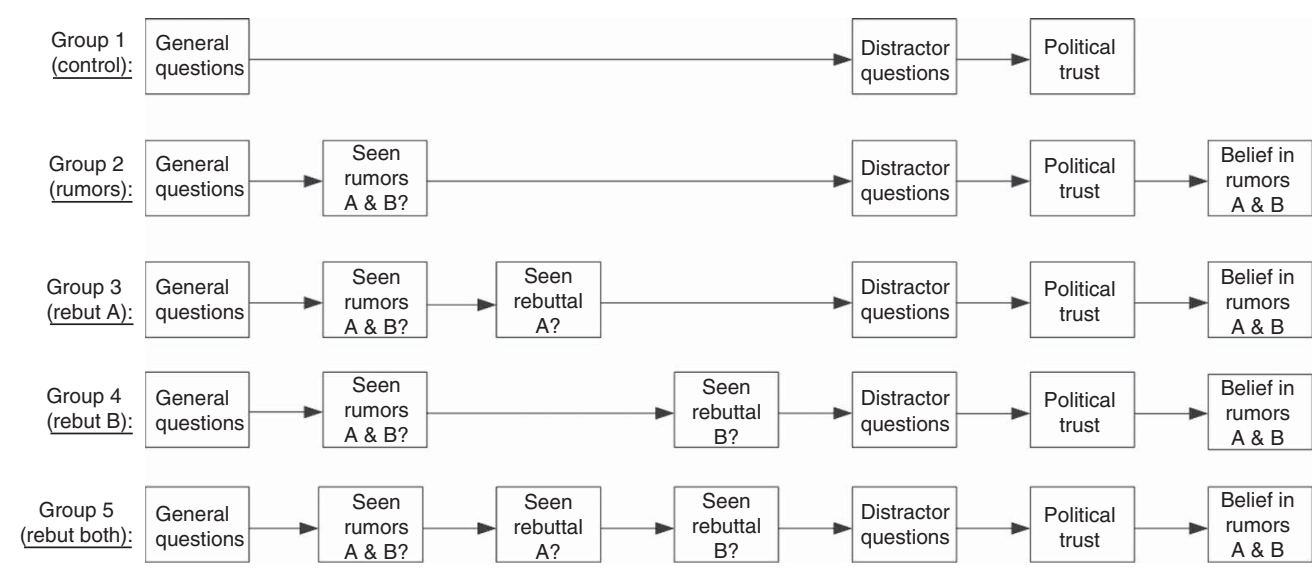

Fig. 1. The procedure of the survey experiments

rebuttal B group; (5) rumors plus both rebuttals group. ${ }^{59}$ This method of grouping is for the sake of mundane realism: given the sheer number of rumors that constantly emerge (with various degrees of circulation), it is impossible for the authorities to catch and rebut the entire universe of rumors; a given internet user will therefore typically come across a sample of rumors, and may see none, some or occasionally all of them rebutted.

All participants were first asked a few general questions about their information consumption habits, political interest, life satisfaction and general political orientations. Then those in the treatment groups were asked whether they had seen various messages before, and were thus given the various rumor/rebuttal treatments (see below). Some distractor questions followed, and then all participants, including those in the control group, were asked to rate their trust in the government on policy issues related to the rumors and their evaluation of China's political system in general. Finally, participants in the treatment groups were asked about their belief in the specific content of the rumors. ${ }^{60}$ See Figure 1 for more details.

For both ethical and political reasons, the study ensured that the survey procedure was an inquiry about the participants' past information exposure. As such, all rumors and rebuttals in the survey experiments were actual rumors and rebuttals from the Chinese internet. ${ }^{61}$ Each treatment was not provided bluntly, but in the form of a question asking whether the respondents had seen the piece of 'information from the internet' before. In addition, labeling rumors as 'information from the internet' rather than 'rumors' ensured the neutrality and naturalness of the treatments.

Using real rumors and rebuttals rather than constructing hypothetical ones meant that it was impractical to compare rebuttals that refute the same rumor but differ in quality or sources. For example, it was difficult to find two real rebuttals of the same rumor that were identical

59 Participants were debriefed after the survey experiments. Those who were asked about the rumors but not the corresponding rebuttals during the surveys were also informed of the rebuttals.

${ }^{60}$ Demographic questions were asked at the end of the survey for all groups to reduce the respondents' wariness when answering the political attitude questions. To avoid priming the subjects and influencing their perceptions of the rumors, the general questions prior to the information treatments did not include trust in the government.

61 Obviously, making up hypothetical rumors and testing them online would put the researcher and participants at considerable risk. Making up rebuttals may seem less risky, but it would still compromise the nature of the survey procedure as an inquiry on the participants' past information exposure. 
except for the source: one from a public figure broadly perceived to be independent of the government, and the other from a (semi-)government entity. ${ }^{62}$ Therefore I selected rebuttals that varied along the two dimensions, conditional on the associated rumors being representative ones from the Chinese internet, and allowed the specific content of the rumors to vary. This choice had its disadvantages for causal inference - the test of the causal mechanism was indirect, and there might be confounds related to the rumors that were not controlled for - but it was made due to several considerations in addition to the obvious ethical and political reasons.

First, while varying the quality and sources of rebuttals to the same rumor can perhaps demonstrate the importance of message quality and source credibility more forcefully, this point has already been established in the psychological and political behavior literatures. The purpose of this study is not to replicate previous research, but to take the importance of message quality and source credibility as given, and then examine whether their effects manifest more clearly at the level of rumor belief or at the level of political attitudes. In fact, the various rebuttals in the experiments did all reduce the participants' belief in the rumors; in other words, they all 'worked'. But effectiveness at the rumor level does not necessarily mean effectiveness at a higher political level, which is a key point of this study. Because the emphasis is not on belief in the specific rumors, it is not imperative to fix the specific rumors and then compare different rebuttals. Instead, we can compare how different rebuttals affect people's political attitudes differently, even if the specifics of the rumors also vary. Secondly, all the rumors in the experiments were typical Chinese online rumors with a similar character: they all used vivid stories accusing the government of some kind of malfeasance or negligence, usually accompanied by pictures. Concerns about potential confounds due to the use of different rumors is thus limited. Lastly, the use of actual rumors and rebuttals can maximize the verisimilitude and realism of the experiments and increase the external validity of the study. Therefore, as a first step in studying the political effects of rumors and rumor rebuttals in an authoritarian country, this research used the above design. Future research, however, can try to move beyond the current study and design alternative practical experimental procedures.

A main potential issue regarding the use of actual rumors is that some participants may have seen them before. This, however, would not be a problem for the study if the proportions of such participants in the various randomized groups were similar, which was verified by randomization checks (see below).

Recruitment. Participants in the two survey experiments were recruited from a popular Chinese crowd-sourcing website for recruiting and compensating agents to perform tasks (www.zhubajie.com), similar to Amazon.com's Mechanical Turk, and then directed to an external survey website where they could take the surveys anonymously. To prevent repetitive participation, each unique IP address and each unique account at the recruiting platform was allowed to participate only once in the experiments.

Because the project studies internet rumors, recruiting subjects online and having them complete the surveys on their own computers in their homes, work places or schools increased the mundane realism of the experiment and the generalizability of the results. ${ }^{63}$ Since this is the first academic study of Chinese politics that recruited subjects from a crowd-sourcing website, ${ }^{64}$

\footnotetext{
${ }^{62}$ I was also constrained by the availability of 'clean' treatments, particularly rebuttals, that were suitable for experiments, rather than haphazard ones containing irrelevant information that often appear on the internet.

63 Iyengar 2011.

64 For another recent experimental study with participants recruited from a Chinese crowd-sourcing website, see Huang (Forthcoming).
} 
however, it is useful to compare the demographics of the research participants and Chinese internet users in general, who are the targets of internet rumors and rebuttals. ${ }^{65}$ As the online appendix shows, participants of this study came from all walks of life, including students, workers (manufacturing, corporate and service), professionals, self-employed and government employees, with the occupational distribution broadly comparable to that of Chinese internet users in general. ${ }^{66}$ They were also from many different age groups and educational backgrounds, and their gender and urban-rural distributions closely mirrored the general internet population. Although the research participants included higher shares of people with a college education and from the twenty to twenty-nine age cohort, they were far more representative of the general internet population than college students, who are often used in political science experiments. The subjects also came from nearly every province of mainland China and thus had a broad geographic representation. Since crowd-sourced experiments have replicated classic and recently published experiment work, ${ }^{67}$ there is little reason to suspect that the reactions of this study's participants to the information treatments would be significantly different from those of the general internet population in China.

A potential challenge to online survey experiments is ensuring that the respondents pay proper attention to the questions; ${ }^{68}$ therefore two methods of quality control were adopted in the study. In the first experiment I recorded the time each participant spent completing the survey and dropped from the analysis those who finished the procedure faster than a pre-determined time threshold. ${ }^{69}$ In the second experiment I set a minimum amount of time for each page of the questionnaire, and was therefore able to use all participants in the analysis. These measures yielded 631 effective participants for the first experiment and 799 for the second.

\section{Experiment 1}

The experiment. The first experiment involved rumors $1 \mathrm{~A}$ and $1 \mathrm{~B}$ and two associated rebuttals, and the participants were randomly assigned to one of five approximately equal-sized groups as discussed above. Balance was achieved on almost all of the covariates including the subjects' prior exposure to each rumor, indicating that the randomization was successful. ${ }^{70}$

The rumor and rebuttal treatments used in the first experiment are shown below. Because the same or similar rumors on Weibo are often posted and reposted by many different users, it is difficult to track down the original source of a rumor. Therefore each rumor treatment began with '@(name omitted)' rather than an actual account name on Weibo. This is fitting in the sense that many online rumors are from anonymous sources, but it also suggests that the current study represents a conservative test of the real effect of rumors, since rumors transmitted from a

\footnotetext{
65 Subjects recruited from the Mechanical Turk have been shown to be more representative of the general public in the United States than in-person convenience samples (Berinsky, Huber, and Lenz 2012). There is no reason to suspect that the most popular online crowd-sourcing platform in China is not as good a subject recruitment tool for studying China as the Mechanical Turk is for studying the United States; users of the Chinese platform are also almost exclusively from China, while some Mechanical Turk users may be from outside the United States but be proficient in English.

${ }^{66}$ In particular, the shares of students were lower than half in both experiments and very close to their share in the general internet population in the second experiment.

67 Berinsky, Huber, and Lenz 2012; Buhrmester, Kwang, and Gosling 2011; Goodman, Cryder, and Cheema 2012; Sprouse 2011.

68 Goodman, Cryder, and Cheema 2012.

69 The results are qualitatively similar with different reasonable time thresholds.

${ }^{70}$ Descriptive statistics of the independent variables and the result of the randomization check are reported in the online appendix.
} 
source known to the recipient are more likely to be believed. ${ }^{71}$ As discussed above, the rumors and rebuttals were also all provided in the form of questions asking whether the respondents had seen the relevant 'information from the internet' before.

Rumor 1A read as follows: @(name omitted): The following are famous pictures of Li-Su children in Yunnan Province crossing the river by zip-line to go to school. Every year a dozen or so kids fall into the roaring $\mathrm{Nu}$ River. The county government says it is a national-level poverty-stricken county and cannot afford 400,000 yuan to build a bridge, but the county party secretary's Audi sedan costs more than 700,000 yuan. ${ }^{72}$

Rebuttal 1A, taken from Weibo's official rumor rebuttal account, read as follows: @WeiboPiyao: [The claim that every year a dozen or so $\mathrm{Li}$-Su children fall into the $\mathrm{Nu}$ River while crossing the river by zip-line to go to school is a false rumor] Yesterday some Weibo users posted pictures of Li-Su kids in Yunnan crossing a river by zip-line to go to school, and alleged that every year a dozen or so children fell into the Nu River. Our investigation shows that these pictures were taken in 2007, and the photographer, @maiquanlaile, told @WeiboPiyao today that as far as he was aware, no children ever fell into the river. Moreover, the local government had already built a bridge after initial media reports. ${ }^{73}$

Rumor 1B read as follows: @(name omitted): The compensation agreement for the Italian victim of the extraordinarily serious accident of the high-speed train crash in Wenzhou on July 23, 2011 has been signed, and the compensation amount is 30 million euros (about 276 million yuan). The compensation for a Chinese citizen, in contrast, is 915,000 yuan. It is reported that the Ministry of Railways made the compensation decision after studying European laws on accidental injuries and deaths. Otherwise the European Union would sue the Chinese government and freeze its assets in Europe and the US. ${ }^{74}$

Rebuttal 1B was also from Weibo's rumor rebuttal account (in the form of a retweet of Sina's official news account): @WeiboPiyao: RT @HeadlineNews: [High-speed train accident handling team: the claim about the foreign victim receiving a particularly high compensation is a false rumor] According to the People's Daily Online, the Ministry of Railways handling team for the July 23rd high-speed train accident said tonight that the online report about the Italian victim receiving 30 million euros as compensation was pure rumor. The Ministry of Railways reiterated that foreign victims of the accident would be compensated according to the same standards as Chinese victims. ${ }^{75}$

These two rumors were very typical of internet rumors in China: they accused the government of some kind of malfeasance, by either omission or commission, with vivid stories and pictures. The two rebuttals were also typical official rebuttals: they denied the rumors in a relatively simple manner, without providing a great deal of evidence, ${ }^{76}$ and the source of the

71 Garrett 2011.

72 The rumor was accompanied by pictures of some children crossing a river by zip-line. The pictures were shown in the survey experiment but are omitted here.

73 See http://weibo.com/1866405545/xyCdn5Fyi for the original rebuttal (last accessed 6 October 2012), which included a link to another page with some limited additional information about the bridge. Because Chinese internet users typically do not click on such links when they browse microblogging posts, particularly on their mobile devices, the link was not activated in the experiment.

74 The rumor was accompanied by a picture of the train crash site, with a picture of a Caucasian-looking woman embedded on the side. The picture was shown in the survey experiment but is omitted here.

${ }^{75}$ See http://e.weibo.com/1866405545/xkotqDKGs for the original rebuttal (last accessed 6 October 2012), which included a link to another page with some brief discussion of the rumor but no additional substantive information. Similar to the case in rebuttal 1A, the link was not activated in the experiment.

76 The statement in the first rebuttal that 'the local government had already built a bridge after initial media reports' also cannot prove that no children had ever fallen into the river before the bridge was built. 
rebuttals was yet to establish an independent reputation due to Weibo's close relationship with the government. The two policy areas directly related to the rumors that all respondents were asked to evaluate were ensuring public safety (related to the children crossing the river rumor) and equal treatment of Chinese and foreign citizens (related to the train crash compensation rumor). ${ }^{77}$ The respondents were also asked to evaluate China's current political system in general. $^{78}$ After these questions on political trust and evaluation, the respondents in the treatment groups (those who were provided with the rumors) were asked about their belief in the rumors. ${ }^{79}$

Note that the children crossing river rumor was about a local government, while the train crash compensation rumor was more directly targeted at a central government ministry, but the survey avoided distinguishing the central government from local governments in questions about the respondents' political trust; instead, it asked about their attitudes toward relevant government policies and the political system in general. This choice was deliberate. While previous studies have argued that Chinese citizens often have a much higher trust in the central government than in local governments, ${ }^{80}$ more recent surveys have shown that this trust differential is no longer as obvious. ${ }^{81}$ More importantly, it has also been shown that the centrallocal difference shown in existing surveys may contain a considerable degree of artificialness, since the respondents' high trust in the central government is often a result of their redefining what constitutes the central government, as well as the nature of the trust, ${ }^{82}$ perhaps due to political sensitivity considerations. Therefore, to avoid priming the respondents to answer the survey questions in ways deemed more politically desirable (that is, local governments are 'bad' but the central government is 'good'), the questionnaire did not explicitly distinguish between levels of government. In addition, this method can help answer whether local issues can also affect citizens' political attitudes toward the government and political system as a whole. If rumors of a local nature also affect the respondents' attitudes toward the government in the whole country, this is further evidence that the Chinese public is (now) placing the locus of responsibility on the entire system rather than any specific level of government, which will contribute to our understanding of evolving political trust in China.

It should also be noted that the train crash compensation rumor contained a real event (the train crash) and a rumored event (the unequal amount of compensation for foreign and Chinese victims), and it can be argued that reminding the participants of the train crash may also decrease their trust in the government on the related issue (public safety). However, the policy question asked about that particular rumor was not public safety, but equal treatment of Chinese and foreign citizens, which is related to the rumored event but not the real event. Therefore, examining whether the rumor and the corresponding rebuttal influenced the respondents' trust in the government on the issue of equal treatment would reveal the effect

\footnotetext{
77 The exact wording was: 'On a scale from 1 to 7 , with 1 being "strongly disagree" and 7 being "strongly agree", indicate the extent to which you agree with the following statements: 1) in general, we can trust our government's work in improving public safety and protecting people's lives and properties; 2) in general, we can trust that our government will provide equal treatment to Chinese citizens and foreign citizens, rather than giving foreign citizens preferential treatment'.

78 'On a scale from 1 to 7 , indicate the extent to which you agree with the following statement: in general, China's current political system is appropriate for the country'.

79 On the compensation rumor, for example, the wording was: 'On a scale from 1 to 7 , to what extent do you think the online report about the foreign victim of Wenzhou high speed train crash getting a compensation of 30 million euros is credible?'.

${ }^{80}$ E.g., Chen 2004; Shi 2001.

81 Zhong 2014.

${ }^{82}$ Li 2013.
} 
(a)

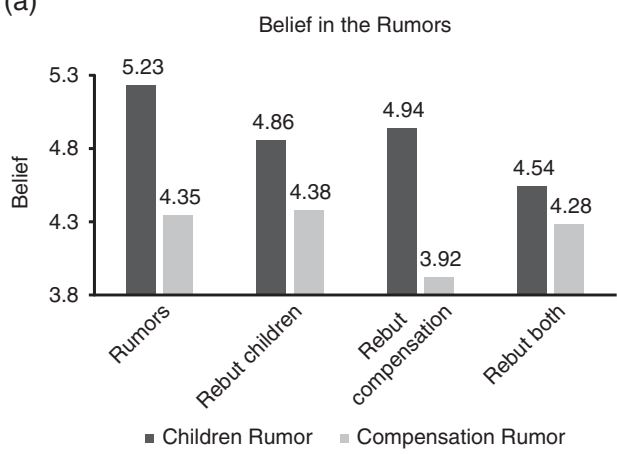

(c)

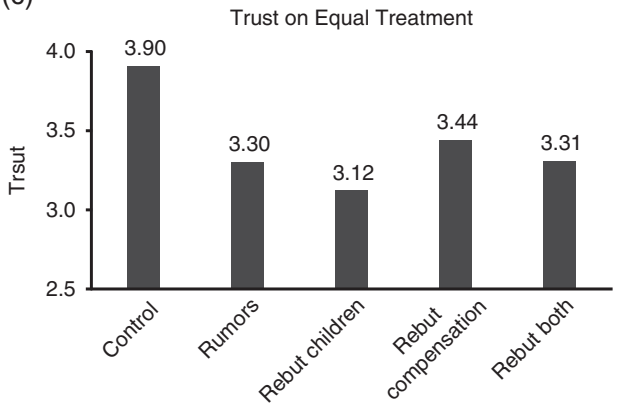

(b)

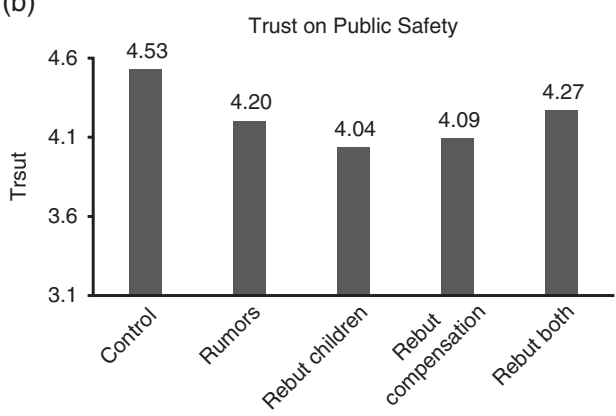

(d)

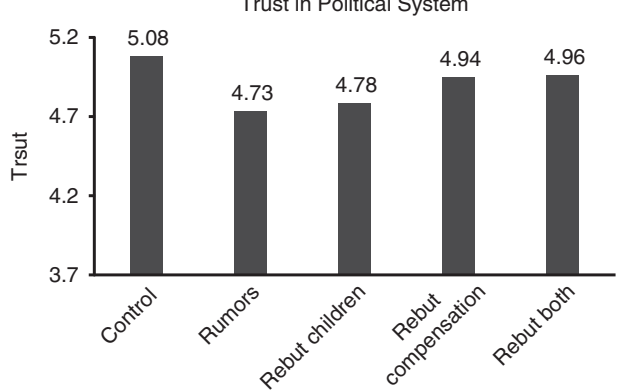

Fig. 2. Group means of rumor belief and political trust (Experiment 1) Note: the range of the Y-axis in each sub-figure is fixed to be 1.5 .

of the rumor component (as well as the rebuttal), rather than the effect of reminding people of the train crash.

Results. Figure 2 and Table 1 present the main results of the first experiment: Figure 2 shows the group means of the dependent variables, ${ }^{83}$ and Table 1 reports the $t$-test results of the group mean differences. Figure 2(a) shows that rebutting a rumor considerably reduced belief in it. Figures 2(b)-2(d) show that the rumors group had clearly lower trust on relevant policy issues and China's political system than the control group, while the various rebuttal groups were not significantly different from the rumors group in such political trust.

The effects of the rumors and non-effects of the rebuttals can be more accurately seen in Table 1 . The first row of the table shows that, relative to the control condition, the rumors significantly reduced the respondents' trust in the government, both in policy areas related to the rumors and in the political system at large. The sizes of the effect ranged from 0.32 to 0.61 points on the sevenpoint scale. Hypothesis 1, regarding the effects of rumors, is thus confirmed. In addition, the children rumor reduced the respondents' trust in the relevant government policy (public safety) in general, indicating that local issues are not just local. The first two cells in that row are blank because the control group was not presented with the rumors and hence not asked about their belief in them.

The second part of Table 1 (between the dashed lines) shows the differences between the various rebuttal groups and the rumors group. The first two columns show the rebuttals' effects

${ }^{83}$ Distributions of the dependent variables in each group are reported in the online appendix. 


\begin{tabular}{|c|c|c|c|c|c|}
\hline & Children rumor belief & Compensation rumor belief & Public safety & Equal treatment & Political system \\
\hline Rumors - Control & & & $-\mathbf{0 . 3 2 3} * *(0.187)$ & $-\mathbf{0 . 6 0 5} * * *(0.228)$ & $-\mathbf{0 . 3 4 8} * *(0.177)$ \\
\hline Rebut children - Rumors & $-0.370 *(0.179)$ & $0.034(0.200)$ & $-0.167(0.195)$ & $-0.180(0.221)$ & $0.051(0.172)$ \\
\hline Rebut compensation - Rumors & $-\mathbf{0 . 2 9 1} *(0.188)$ & $-\mathbf{0 . 4 2 5} * *(0.199)$ & $-0.110(0.189)$ & $0.142(0.221)$ & $0.213(0.176)$ \\
\hline Rebut both - Rumors & $-\mathbf{0 . 6 8 6} * * *(0.199)$ & $-0.067(0.206)$ & $0.066(0.191)$ & $0.006(0.215)$ & $0.225(0.180)$ \\
\hline Rebut children - Control & & & $-\mathbf{0 . 4 9 1 * * * ( 0 . 1 9 0 )}$ & $-\mathbf{0 . 7 8 5} * * *(0.223)$ & $-0.296 *(0.167)$ \\
\hline Rebut compensation - Control & & & $-\mathbf{0 . 4 3 4 * * * ( 0 . 1 8 4 )}$ & $-\mathbf{0 . 4 6 3} * *(0.223)$ & $-0.135(0.171)$ \\
\hline Rebut both - Control & & & $-\mathbf{0 . 2 5 7} *(0.187)$ & $-\mathbf{0 . 5 9 9} * * *(0.216)$ & $-0.122(0.174)$ \\
\hline
\end{tabular}

Notes: entries in the parentheses are standard errors. The $t$-tests are under the assumption of unequal variances, and the associated $p$-values reflect onesided hypothesis tests. $* * * p<0.01, * * p<0.05, * p<0.10$. The differences in political attitudes between the rebuttal groups and the rumors group are shaded to emphasize their lack of statistical significance, in contrast to the entries in Table 4. 
on belief in the rumors. As expected, rebutting the children rumor reduced the subjects' belief in that rumor, and rebutting the compensation rumor reduced belief in the corresponding rumor. Rebutting both rumors also reduced the subjects' belief in one of the rumors. ${ }^{84}$ The effect sizes ranged from 0.37 to 0.69 points. The hypothesis regarding the effects of rebuttals on people's belief in the specific content of rumors, Hypothesis 2, is also confirmed.

More importantly, the shaded entries in Table 1 show the differences between the rebuttal groups and the rumors group with regards to political trust. While the first row of Table 1 has shown that rumors reduced the respondents' trust in the government and state, the shaded entries show that rebuttals (either rebutting one or both rumors) had no statistically significant effect on their political trust, whether in policy areas related to the rumors or in the political system as a whole. The results were thus consistent with Hypothesis 3a: simple or perfunctory rebuttals from a source close to the government would not be effective in improving people's political trust.

While the study's hypotheses about political trust (Hypotheses $3 \mathrm{a}$ and $3 \mathrm{~b}$ ) refer to the differences between the rebuttal groups and the rumors group, it is also instructive to compare the rebuttal groups with the control group, as in the last three rows of Table 1. Consistent with the findings above, the rebuttal groups in general had significantly lower political trust than the control group, meaning that these groups' political trust, weakened by the rumors (compared to the control condition), was not improved by the rebuttals. The only partial exception was their trust in the entire political system for the 'rebut compensation' group and 'rebut both' group. These two groups' trust in the political system was halfway between those of the control group and the rumors group, and was statistically indistinguishable from either group. This suggests that the rebuttals somewhat increased these two groups' trust in the political system from the rumors condition, but that the difference was not sufficient to clearly differentiate them from the rumors group. Looking across all dependent variables and all groups, then, it is evident that the relatively weak rebuttals in experiment 1 generally did not improve citizens' political trust that had been damaged by rumors, which was consistent with Hypothesis $3 \mathrm{a}$, although they were not always completely futile.

To check the robustness of the above results and to see the effects of the covariates, I ran ordered probit regressions on the subjects' belief in the specific rumors and their political trust. $^{85}$ In all the regressions I include the usual socio-demographic variables, ${ }^{86}$ political affiliation (CCP membership), news consumption, ${ }^{87}$ political interest, ${ }^{88}$ life satisfaction ${ }^{89}$ and

${ }^{84}$ Interestingly, rebutting the compensation rumor also reduced the subjects' belief in the children rumor, which suggests that rebuttals can sometimes have spillover effects: they may reduce people's belief in rumor communications in general. This result, however, is only significant at the one-sided 0.1 level. On the other hand, rebutting both rumors in the experiment did not reduce the subjects' belief in the compensation rumor, which suggests that having every rumor rebutted may sometimes lead the message recipients to suspect that the authorities are simply rebutting everything regardless of the truth. Under such circumstances, rebutting some rather than all rumors can increase the effectiveness of the rebuttals. These subtle results are beyond the scope of this article, but should be investigated in future research. What is important for the present article is that discretely rebutting a rumor reduced the subjects' belief in it.

${ }^{85}$ I also ran OLS regressions, and the results were consistent with ordered probit regressions.

86 See the online appendix for descriptive demographic statistics.

87 Question wording: 'How often do you follow news in the media?'. The choices were: 'almost everyday', 'several times per week', 'once or twice per week', 'less than once a week' and 'rarely'.

88 Question wording: 'How interested are you in political affairs?'. The choices were 'interested', 'somewhat interested', 'not very interested' and 'not interested at all'.

${ }^{89}$ Question wording: 'All things considered, how do you feel about your life, work, and study these days?'. The choices were 'satisfied', 'somewhat satisfied', 'somewhat dissatisfied' and 'dissatisfied'. 
TABLE 2 Ordered Probit Analysis of Rumor Belief (Experiment 1)

\begin{tabular}{lrr}
\hline \hline & Children rumor belief & Compensation rumor belief \\
\hline Rebut children & $\mathbf{- 0 . 3 1 8 * * ( 0 . 1 3 1 )}$ & $0.001(0.130)$ \\
Rebut compensation & $-0.215(0.132)$ & $\mathbf{- 0 . 3 0 4 * * ( 0 . 1 3 0 )}$ \\
Rebut both & $-\mathbf{0 . 4 9 7 * * * ( 0 . 1 3 4 )}$ & $-0.055(0.132)$ \\
News & $0.005(0.041)$ & $-0.057(0.041)$ \\
Political interest & $-0.118^{*}(0.062)$ & $-0.027(0.062)$ \\
Life satisfaction & $-0.018(0.065)$ & $-0.028(0.064)$ \\
Pro-West & $0.056^{*}(0.034)$ & $0.001(0.034)$ \\
Age & $-0.010(0.009)$ & $-0.007(0.009)$ \\
Male & $0.200^{* *}(0.099)$ & $0.054(0.097)$ \\
Education & $0.045(0.054)$ & $0.074(0.054)$ \\
Income & $0.098(0.073)$ & $-0.006(0.073)$ \\
CCP member & $-0.067(0.145)$ & $0.020(0.144)$ \\
\hline Observations & 506 & 506 \\
\hline \hline
\end{tabular}

Notes: the baseline group is 'rumors'. Standard errors in parentheses. Cut points are almost always statistically significant, but omitted here for space consideration. ${ }^{* *} p<0.01,{ }^{* *} p<0.05,{ }^{*} p<0.10$. $P$-values reflect two-sided hypothesis tests.

prior political attitudes. ${ }^{90}$ Prior political attitudes were measured by the respondents' pro-Western orientation, which is conceptually clearer in contemporary China than positions on the liberal-conservative ideology dimension. ${ }^{91}$

Table 2 shows the results of ordered probit regressions on the subjects' belief in the rumors, with the rumors group being the baseline. The results are consistent with the $t$-tests in Table 1: rebutting a rumor reduced the subjects' belief in the specific content of that rumor. Another interesting result also emerges from Table 2: socio-economic and political backgrounds including education, income, life satisfaction, consumption of mainstream (official) news and even communist party membership were not correlated with one's belief in the rumors in any significant way. Age did not matter either, while males had a higher belief than females in one of the rumors; as the second experiment will show, however, this gender effect exists only occasionally. In other words, citizens of diverse socio-economic, political and demographic backgrounds are similarly susceptible to anti-government rumors. This result further attests to the significance of rumors in authoritarian countries. In well-established democracies, better-educated and more politically sophisticated citizens are more likely to embrace mainstream norms and information, and hence less likely to believe rumors. ${ }^{92}$ In addition, people are more likely to believe rumors implicating a political party they do not support. ${ }^{93}$ In a one-party authoritarian system, however, official information and media are widely

\footnotetext{
${ }^{90}$ One's prior exposure to the rumors cannot be added as controls in regressions on political trust in which the control group is the baseline, because subjects in this group were not asked about rumors. Thus including such variables would lead to a collinearity problem. Controlling for prior exposure in regressions on one's belief in the rumors, where the rumors group is the baseline, does not change the results reported here.

${ }^{91}$ Pro-Western orientation was measured as the sum of a respondent's degree of agreement with the following two statements, with responses to the second statement reversely coded: (1) 'We must strive to learn from the West in terms of institutions, culture, and ideas' and (2) 'We must strive to maintain our own institutions, culture, and way of life'.

92 Berinsky 2012.

${ }^{93}$ Weeks and Garrett 2014.
} 
TAв LE $3 \quad$ Ordered Probit Analysis of Political Trust (Experiment 1)

\begin{tabular}{lrrr}
\hline \hline & \multicolumn{1}{c}{ Public safety } & \multicolumn{1}{c}{ Equal treatment } & \multicolumn{1}{c}{ Political system } \\
\hline Rumors & $\mathbf{- 0 . 2 3 5 * ( 0 . 1 3 1 )}$ & $\mathbf{- 0 . 4 0 2 * * * ( 0 . 1 3 2 )}$ & $\mathbf{- 0 . 2 5 9 * * ( 0 . 1 3 2 )}$ \\
Rebut children & $\mathbf{- 0 . 3 6 7 * * * ( 0 . 1 2 9 )}$ & $\mathbf{- 0 . 5 4 1 * * * ( 0 . 1 3 1 )}$ & $\mathbf{- 0 . 2 6 7 * * ( 0 . 1 3 0 )}$ \\
Rebut compensation & $\mathbf{- 0 . 2 8 4 * * ( 0 . 1 3 0 )}$ & $\mathbf{- 0 . 2 7 9 * * ( 0 . 1 3 1 )}$ & $-0.153(0.132)$ \\
Rebut both & $-0.217(0.133)$ & $\mathbf{- 0 . 4 0 1 * * * ( 0 . 1 3 3 )}$ & $-0.133(0.134)$ \\
News & $0.075 * *(0.037)$ & $-0.001(0.037)$ & $-0.019(0.037)$ \\
Political interest & $0.002(0.055)$ & $-0.034(0.056)$ & $0.138^{* *}(0.056)$ \\
Life satisfaction & $0.298^{* * *}(0.059)$ & $0.289 * * *(0.059)$ & $0.126 * *(0.059)$ \\
Pro-West & $-0.031(0.030)$ & $-0.032(0.030)$ & $-0.153 * * *(0.030)$ \\
Age & $-0.003(0.008)$ & $-0.006(0.008)$ & $-0.009(0.009)$ \\
Male & $-0.032(0.088)$ & $-0.150 *(0.089)$ & $-0.027(0.089)$ \\
Education & $-0.080(0.049)$ & $-0.119 * *(0.049)$ & $0.059(0.049)$ \\
Income & $0.139 * *(0.066)$ & $0.020(0.066)$ & $0.159 * *(0.066)$ \\
CCP member & $0.047(0.127)$ & $0.159(0.127)$ & $0.028(0.128)$ \\
\hline Observations & 631 & 631 & 631 \\
\hline \hline
\end{tabular}

Notes: the baseline group is 'control'. Standard errors in parentheses. Cut points are almost always statistically significant, but omitted here for space consideration. $* * * p<0.01, * * p<0.05, * p<0.10$. $P$-values reflect two-sided hypothesis tests.

regarded as biased propaganda. Therefore, rumors as alternative 'truth' have broad appeal in an authoritarian country, including among members of the ruling party. ${ }^{94}$ Unsurprisingly, pro-Western orientation increased the participants' belief in one of the rumors, a point that we will return to after the second survey experiment.

Table 3 shows the results of ordered probit regressions on the subjects' political trust, with the control group as the baseline. The results are also consistent with the $t$-tests in Table 1: rumors significantly reduced the subjects' trust in the government in policy areas related to the rumors, as well as their support of the political system as a whole. The rebuttals groups in general also had significantly lower trust than the control group, indicating that rebuttals largely failed to recover the subjects' political trust. The table also shows that consumption of mainstream news boosted the respondents' political trust in only one of the three cases (in the second experiment this occasional effect disappeared altogether), suggesting that officially sanctioned news in an authoritarian country may have lower influence on public opinion than unofficial information. The results of other variables are generally expected.

In sum, in the first experiment rumors eroded the participants' trust in the government and support of the regime. Rebutting a rumor reduced the participants' belief in the specific content of the rumor. With regards to recovering their political trust and support, however, these relatively simple and quasi-official denials generally failed.

\section{Experiment 2}

The experiment. To further examine the effects of rumors and to see if stronger rebuttals that are detailed/vivid or from a public figure perceived to be independent of the government can be more effective in neutralizing the political influence of rumors, I conducted a second survey

${ }^{94}$ See also Bauer and Gleicher 1953. 
experiment, using the same procedure as the first one but rumors $2 \mathrm{~A}$ and $2 \mathrm{~B}$ and their associated rebuttals. Balance was achieved on all of the covariates in the second experiment.

Rumor 2A was about the Chinese government's (lack of) protection of Chinese citizens abroad:"95@(name omitted): In the American passport, there is the following sentence: 'No matter where you are, the United States government is always behind you'. In the Chinese passport the sentence is the following: 'Please strictly comply with local laws and respect the customs there'. Micro comment: the United States says 'If someone bullies you when you are abroad, just let me know and I will fix that guy'; China says 'Behave yourself when you are abroad; follow their rules and do not bring me troubles.96

This rumor can be shown to be false by examining Chinese and American passports, but it nevertheless received a fairly high degree of belief among the Chinese public, perhaps due to the relatively low percentage of Chinese citizens with overseas travel experience and hence possession of a passport. The rebuttal of the rumor came from a police department in Nanjing Municipality, which has maintained an active presence on Weibo using the account @JiangningGong'anZaixian (Jiangning Police Online). The rebuttal, accompanied by several photos of the relevant pages of Chinese and American passports, which were shown in the experiment but are omitted here, provided detailed information in a vivid manner (one detail showed that the real situation was actually somewhat opposite to the allegation of the rumor): @ JiangningGong'anZaixian: The alleged difference between Chinese and American passports is a false rumor. The first page of the American passport says (in English, French, and Spanish): 'The Secretary of State of the United States of America hereby requests all whom it may concern to permit the citizen/national of the United States named herein to pass without delay or hindrance and in case of need to give all lawful aid and protection'. The first page of the Chinese passport says: 'The Ministry of Foreign Affairs of the People's Republic of China requests all civil and military authorities of foreign countries to allow the bearer of this passport to pass freely and afford assistance in case of need'. Later in the American passport there is a section called 'Important Information', but it does not contain any sentence to the effect of 'No matter where you are, the United States government is always behind you'. The Chinese passport does not contain the sentence 'Please strictly comply with local laws and respect the customs there'. In fact, there is a sentence 'Avoid violating foreign laws' written in the 'Important Information' section of the American passport. ${ }^{97}$

Rumor 2B was ostensibly about a traffic accident involving a luxury sports car (Ferrari), but it clearly alluded to the profligate lifestyles and suspicious income sources of some Chinese government officials' family members; the related policy issue is whether the government will restrict officials' family members from improperly enriching themselves through government connections: ${ }^{98} @$ (name omitted): At 4 AM on May 12th, a speeding red Ferrari sports car ran a red light at an intersection in Singapore, crashing into a taxi. Apart from the Ferrari owner

\footnotetext{
95 The relevant trust question asked the respondents to what extent they agreed with the following statement: 'In general, we can trust that our government will protect the interests of Chinese citizens abroad just as well as how the government of a developed foreign country would protect their citizens'.

96 The rumor was accompanied by a picture showing the cover of the Chinese passport on the left and the personal information page of a US passport on the right. The picture was shown in the experiment but is omitted here.

97 The original rebuttal by Jiangning Police Online was part of a collective rebuttal of ten online rumors. See http://www.weibo.com/1113218211/yfvTrr0Kq (last accessed 6 October 2012).

98 The wording of the trust question was: 'Indicate the extent to which you agree with the following statement: In general, we can trust that our government officials will restrict their family members not to enrich themselves through improper means or engage in other inappropriate behavior'.
} 
who died on the spot, the fifty-two-year-old Singaporean taxi driver and a Japanese passenger in the taxi also died after being taken to the hospital. The United Evening News of Singapore says the owner of the Ferrari sports car was a thirty-one-year-old Chinese man from Sichuan named Ma Chi, who went to Singapore in 2008, engaged in finance and investment activities, and was in the process of applying for permanent residency. Internet users have found through human flesh searching that Ma Chi's father is likely a high-level official of the State Council. ${ }^{99}$

The rebuttal of this rumor came from Ren Zhiqiang, a real estate developer who had become a household name in China for his frequent and outspoken criticism of government policies, which had earned him the nickname 'Ren Dapao' (Cannon Ren). Although Ren Zhiqiang was initially known for his opinions on real estate issues, in recent years his sharp criticism has extended to many other areas including political reform, government corruption and freedom of speech, as shown clearly in his prolific Weibo posts. As a result, he has been invited to drink tea' (a Chinese euphemism for being questioned by the authority). ${ }^{100}$ The rebuttal was as follows: @ RenZhiqiang: A few days ago a Chinese man with the surname Ma was involved in a car crash in Singapore, and then many idlers from domestic and foreign media as well as the internet started the nonsense that he was the son of Ma Kai, the General Secretary of the State Council. Ma Kai was once the deputy chief of the Xicheng District. He has no son at all; how come he suddenly has a son from Sichuan? Whenever something bad happens, some people believe it must be related to a high-level Chinese official. What damn logic is this? Everyone who knows the truth should fight with this sort of nonsensical rumors and fabrications. ${ }^{101}$

Results. Figure 3 and Table 4 present the main results of the second experiment. Figure $3 \mathrm{a}$ shows that rebutting a rumor considerably reduced belief in it, although a fair amount of belief remained. Figures $3 b-3 d$ show that rumors reduced the respondents' trust in citizen protection and China's political system, although their trust in officials' families was not reduced in the rumors condition. This is most likely because, as Figure $3 \mathrm{c}$ shows, respondents' trust in government officials disciplining their family members was low even without rumors (2.4 on the seven-point scale, significantly lower than their trust on all other issues in the two experiments), which is consistent with the common perception about official corruption in China. As a result, there was little room for this trust to be reduced further by rumors. These results are similar to those in the first experiment. Different from the situation in the first experiment, however, Figures $3 b-3 d$ show that some rebuttals in the second experiment clearly recovered the respondents' political trust. For example, rebutting the passport rumor recovered trust in citizen protection, rebutting the Ferrari rumor improved trust in government officials' families and rebutting both rumors recovered trust in the political system.

The effects of rumors and rebuttals are more accurately shown in the $t$-tests of group mean differences in Table 4. The first row of the table shows that, with the exception of trust in officials' families, rumors reduced the subjects' trust in government policies and the political system, again consistent with Hypothesis 1. The second part of Table 4 (between the dashed lines) shows the differences between the various rebuttal groups and the rumors group. The first

\footnotetext{
99 The rumor was accompanied by a photo of a car crash site, which was shown in the experiment but is omitted here. The State Council is China's cabinet.

${ }^{100}$ See his Weibo post http://www.weibo.com/1182389073/zdq2cDPg5 (last accessed 22 March 2013). He continued to speak out after the incident.

101 See http://www.weibo.com/1182389073/yl6wRkFCw for the original rebuttal (last accessed 6 October 2012).
} 
(a)

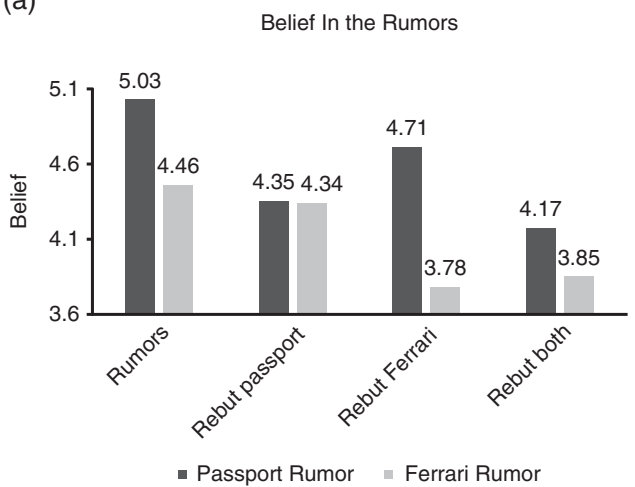

(c)

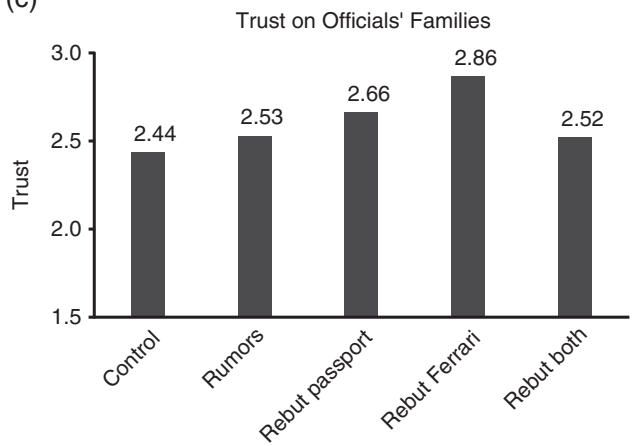

(b)

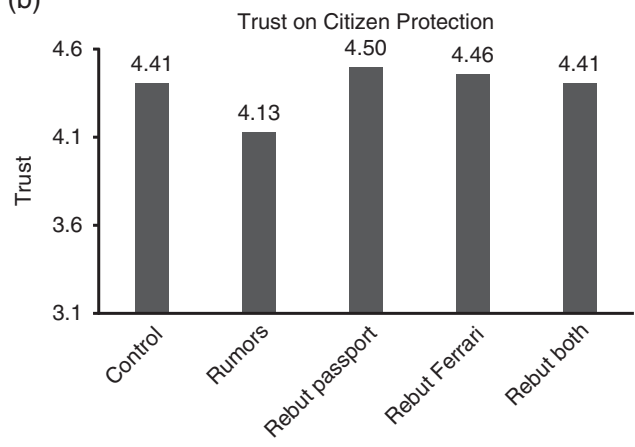

(d)

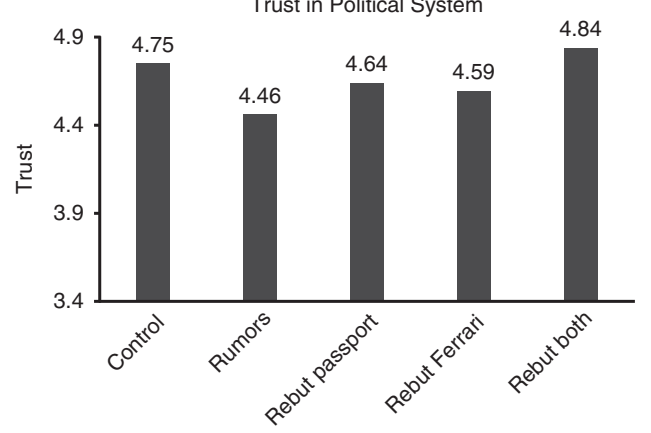

Fig. 3. Group means of rumor belief and political trust (Experiment 2)

Note: the range of the $\mathrm{Y}$-axis in each sub-figure is fixed to be 1.5.

two columns show the rebuttals' effects on belief in the rumors. As expected, rebutting the passport rumor reduced the subjects' belief in that rumor, and rebutting the Ferrari rumor reduced belief in the corresponding rumor. Furthermore, rebutting both rumors reduced the subjects' belief in both rumors. ${ }^{102}$ Hypothesis 2 is thus again confirmed.

More importantly, the shaded entries in Table 4 show the differences between the rebuttal groups and the rumors group in political trust. The detailed and vivid rebuttal of the passport rumor significantly increased the respondents' trust in the Chinese government on citizen protection. The rebuttal of the Ferrari rumor by the well-known government critic Ren Zhiqiang also significantly increased the subjects' trust in the issue of government officials disciplining their family members. Having both rumors rebutted increased the subjects' trust in the entire political system as well as their trust in citizen protection. Hypothesis $3 \mathrm{~b}$ is thus confirmed: strong rebuttals that are detailed and vivid, or from a source with a reputation of being independent, can recover people's political trust, in sharp contrast to the non-effects of weak rebuttals on political trust in the first experiment.

It is also instructive to compare the political attitudes of the rebuttal groups and the control group, shown in the last three rows of Table 4 . The rebuttal groups generally had similar levels of political

102 Rebutting the Ferrari rumor also reduced the subjects' belief in the passport rumor and the corresponding trust on citizen protection, again suggesting that rebuttals can sometimes have subtle spillover effects, which is worth further research. 
TA B LE 4 Group Mean Differences in Rumor Belief and Political Trust (Experiment 2)

\begin{tabular}{|c|c|c|c|c|c|}
\hline & Passport rumor belief & Ferrari rumor belief & Citizen protection & Officials' family & Political system \\
\hline Rumors - Control & & & $\mathbf{- 0 . 2 7 5} *(0.185)$ & $0.092(0.170)$ & $-\mathbf{0 . 2 9 0} * *(0.158)$ \\
\hline Rebut passport - Rumors & $-\mathbf{0 . 6 7 5} * *(0.193)$ & $-0.118(0.185)$ & $\mathbf{0 . 3 6 8} *(0.185)$ & $0.136(0.179)$ & $0.178(0.169)$ \\
\hline Rebut Ferrari - Rumors & $-\mathbf{0 . 3 1 6} *(0.199)$ & $-\mathbf{0 . 6 7 9} * * *(0.191)$ & $\mathbf{0 . 3 2 7} * *(0.191)$ & $0.338 * *(0.185)$ & $0.133(0.172)$ \\
\hline Rebut both - Rumors & $\mathbf{- 0 . 8 5 7 * * * ( 0 . 1 9 5 )}$ & $\mathbf{- 0 . 6 0 8} * * *(0.188)$ & $0.275 *(0.187)$ & $-0.007(0.173)$ & $0.379 * *(0.164)$ \\
\hline Rebut passport -Control & & & $0.093(0.174)$ & $\mathbf{0 . 2 2 8} *(0.164)$ & $-0.112(0.157)$ \\
\hline Rebut Ferrari - Control & & & $0.052(0.181)$ & $\mathbf{0 . 4 3 0} * * * *(0.170)$ & $-0.157(0.161)$ \\
\hline Rebut both - Control & & & $-0.000(0.177)$ & $0.085(0.157)$ & $0.089(0.152)$ \\
\hline
\end{tabular}

Notes: measures are on a scale from 1 to 7 . Entries in the parentheses in the upper panel are standard deviations and those in the lower panel are standard errors. $T$-tests of the mean difference estimates are under the assumption of unequal variances, and the associated $p$-values reflect one-sided hypothesis tests. ${ }^{* *} p<0.01, * * p<0.05,{ }^{*} p<0.10$. The differences in political attitudes between the rebuttal groups and the rumors group are shaded to emphasize the statistically significant results, in contrast to the entries in Table 1. 
TAвLE $5 \quad$ Ordered Probit Analysis of Rumor Belief (Experiment 2)

\begin{tabular}{lrr}
\hline \hline & Passport rumor belief & Ferrari rumor belief \\
\hline Rebut passport & $\mathbf{- 0 . 4 2 3 * * * ( 0 . 1 1 4 )}$ & $-0.093(0.112)$ \\
Rebut Ferrari & $\mathbf{- 0 . 2 1 9 * ( 0 . 1 2 1 )}$ & $\mathbf{- 0 . 4 1 4 * * * ( 0 . 1 2 0 )}$ \\
Rebut both & $\mathbf{- 0 . 5 1 3 * * * ( 0 . 1 1 8 )}$ & $-\mathbf{0 . 3 6 3} * * *(0.116)$ \\
News & $0.018(0.037)$ & $0.011(0.037)$ \\
Political interest & $0.081(0.055)$ & $0.045(0.055)$ \\
Life satisfaction & $-0.082(0.052)$ & $-0.011(0.052)$ \\
Pro-West & $0.063 * *(0.032)$ & $0.060^{*}(0.031)$ \\
Age & $0.011(0.009)$ & $-0.016^{*}(0.009)$ \\
Male & $-0.067(0.087)$ & $0.054(0.086)$ \\
Education & $0.054(0.048)$ & $0.068(0.048)$ \\
Income & $-0.041(0.064)$ & $-0.042(0.063)$ \\
CCP member & $-0.126(0.123)$ & - \\
\hline Observations & 622 & $6.158(0.122)$ \\
\hline \hline
\end{tabular}

Notes: the baseline group is 'Rumors'. Standard errors in parentheses. Cut points are almost always statistically significant, but are omitted here for space consideration. $* * * p<0.01, * * p<0.05$, $* p<0.10$. $P$-values reflect two-sided hypothesis tests.

trust as the control group, meaning that these groups' political trust was recovered by the strong rebuttals (from the negative influence of the rumors). In the case of the 'rebut Ferrari' group's trust in officials' families, the rebuttal group had higher trust than the control group, because the respondents' trust on this issue started at a low level, which rumors could not reduce further. The rebuttal from the government critic elevated the subjects' trust above that of the control group because it provided credible information or arguments favorable to the government. These rebuttalcontrol comparison results were again in sharp contrast to those in the first experiment, which showed that groups receiving weak rebuttals still had significantly lower trust than the control group.

For a robustness check and to see the effects of the covariates, I ran ordered probit regressions on the subjects' belief in the specific content of the rumors and their political trust. Table 5 shows the results for rumor belief, with the rumors group serving as the baseline. The results are clearly consistent with the $t$-tests in Table 4 . Moreover, Table 5 again shows that socioeconomic and political backgrounds including education, income, life satisfaction, news consumption and even CCP membership were not correlated with one's belief in the rumors. Reviewing Tables 2 and 5 together also shows that age and gender generally do not matter in people's belief in the rumors either. The only control variable that has a relatively consistent effect on rumor belief is pro-Western orientation: it increased belief in three of the four rumors.

Table 6 shows the results of ordered probit regressions on political trust, with the control group as the baseline. The results are again consistent with the above $t$-tests: relative to the control group, rumors significantly reduced the subjects' trust in the government and the political system, except on the issue on which the social trust was already low in the absence of rumors (officials' families). In cases where rumors reduced political trust, there was no significant difference in political trust between the rebuttals groups and the control group, indicating that these strong rebuttals generally recovered the subjects' political trust that had previously been damaged by the rumors. In terms of the trust in officials' families, the rebuttal from the government critic ('rebut Ferrari') elevated the subjects' trust above that of the control group, again showing the effectiveness of a strong rebuttal. Consumption of mainstream news had no effect on the respondents' political trust. The results of other variables were generally as expected. 
TABLE 6 Ordered Probit Analysis of Political Trust (Experiment 2)

\begin{tabular}{lrrr}
\hline \hline & Citizen protection & Officials' families & \multicolumn{1}{c}{ Political system } \\
\hline Rumors & $\mathbf{- 0 . 2 0 5 *}(0.112)$ & $-0.001(0.117)$ & $\mathbf{- 0 . 2 2 1 * *}(0.112)$ \\
Rebut passport & $0.047(0.110)$ & $0.136(0.115)$ & $-0.045(0.111)$ \\
Rebut Ferrari & $0.008(0.118)$ & $\mathbf{0 . 2 9 4 * * ( 0 . 1 2 2 )}$ & $-0.125(0.119)$ \\
Rebut both & $-0.041(0.114)$ & $0.060(0.119)$ & $0.036(0.115)$ \\
News & $-0.019(0.032)$ & $0.052(0.033)$ & $0.007(0.032)$ \\
Political interest & $0.086^{*}(0.048)$ & $-0.043(0.050)$ & $0.040(0.048)$ \\
Life satisfaction & $0.192^{* * *}(0.045)$ & $0.216^{* * *}(0.046)$ & $0.117 * * *(0.045)$ \\
Pro-West & $-0.071^{* *}(0.028)$ & $-0.065^{* *}(0.029)$ & $-0.132^{* * *}(0.028)$ \\
Age & $0.008(0.008)$ & $-0.022^{* * *}(0.008)$ & $-0.013^{*}(0.008)$ \\
Male & $0.021(0.076)$ & $-0.018(0.079)$ & $0.040(0.077)$ \\
Education & $-0.050(0.042)$ & $0.035(0.044)$ & $-0.009(0.042)$ \\
Income & $0.124 * *(0.057)$ & $0.195^{* * *}(0.061)$ & $0.204 * * *(0.057)$ \\
CCP member & $0.261^{* *}(0.110)$ & $0.130(0.112)$ & $0.290^{* * *}(0.110)$ \\
\hline Observations & 799 & 799 & 799 \\
\hline \hline
\end{tabular}

Notes: the baseline group is 'Control'. Standard errors in parentheses. Cut points are almost always statistically significant, but omitted here for space consideration. ${ }^{* *} p<0.01, * * p<0.05,{ }^{*} p<0.10$. $P$-values reflect two-sided hypothesis tests.

In sum, the rebuttals in the second experiment were much stronger than those in the first experiment: they either contained detailed and vivid evidence or came from a source widely perceived to be independent of the government. As a result, they yielded more positive results in improving the respondents' trust in and support of the government.

\section{DISCUSSION AND CONCLUSION}

Rumors are highly prevalent, visible and politically significant in authoritarian countries, and yet there has been a dearth of studies about their political effects in such countries and whether rumors can be effectively countered, perhaps due to the difficulty of studying something that is usually informal, mercurial and transmitted via whispers. The spread of the internet and especially social media, where rumors are openly posted and reposted in roughly similar written forms, offers an opportunity to carefully study this important phenomenon. This article provides such a study with representative rumors and rebuttals from the Chinese internet. The use of real rumors and rebuttals as well as the online environment of the survey procedure considerably increased the external validity of the experiments. The findings here are therefore close to the effects of a real information war rather than a hypothetical one.

The results of this study contribute to our understanding of both misinformation and rumors in general and the information politics in authoritarian countries in particular. While the current results corroborate some aspects of the previous research in social psychology on rumors, namely that the quality and sources of rebuttals matter a great deal in the effectiveness of rebuttals, they also reveal a crucial point that has been largely neglected. Previous scholarship has focused on how different types of rebuttals affect people's belief in the specific content of the rumors, not how they affect citizens' political attitudes. The current results show that the divergent effects of different types of rebuttals operate more on the political and policy dimension than on the specific content of rumors: beliefs in the rumors themselves are generally responsive to correction, but the effects of rebuttals on recovering citizens' trust in the government on larger political and policy issues underlying the rumors are far less consistent. 
This finding suggests that researchers on rumors and misinformation, as well as practitioners aiming to improve government-society trust, should pay more attention to social and political factors that give rise to misinformation and rumors in the first place, rather than treat them as isolated phenomena. It should especially be the case in an authoritarian context, where rumors are ubiquitous, and citizens of diverse demographic, socio-economic and even political backgrounds believe rumors similarly, apparently because the concerns and anxiety over political and policy issues are widespread.

In terms of our understanding of authoritarian information politics, the study expands the existing literature which is predominantly focused on communications from the government or its censorship of information, and shows a nuanced picture of information politics in such countries: on the one hand citizens of diverse backgrounds are similarly susceptible to antiregime messages including false information originating from the society, which reduces their trust and support of the government, and on the other hand the authorities can counter the influence of such messages, if the counter messages are well-evidenced and forceful, or issued by sources broadly perceived to be independent from the government.

It would be improper to conclude, however, that to combat rumors the government can simply produce high-quality rebuttals or have independent and well-known public figures refute the rumors. For one thing, even in such cases the government can only reduce but not eliminate citizens' belief in rumors. Moreover, as is well known to observers of Chinese social media, rumors are typically much more widely forwarded and reposted than rebuttals. Perhaps most importantly, powerful and persuasive rebuttals are often not feasible to obtain. With regards to the quality of rebuttals, most rumors are about situations that are inherently ambiguous, for which high-quality rebuttals are hard to come by. Take the train crash compensation rumor for example. It is difficult to conclusively prove to internet users that the government did not provide thirty million euro in compensation to the family of the foreign victim. Even if the victim's family would issue a statement denying the amount of the compensation, internet users could suspect that the family had been bought off by the Chinese government in making the statement. As for having independent public figures refute rumors, for example Ren Zhiqiang refuting the Ferrari rumor, the effectiveness of these individuals hinges on the crucial condition that they are usually critical of the government and rarely speak for it (in fact, Ren Zhiqiang himself has sometimes been accused by government supporters of spreading rumors). To have them come to the government's defense (voluntarily or otherwise) whenever there is a unfavorable rumor would destroy their very reputation as government critics and hence the effectiveness of their rebuttals.

Therefore, convincing rebuttals or support from public figures perceived to be independent are often not available to the government. As a defender in this war of (mis)information, the government is inevitably in a disadvantaged position, and rebuttals can at most contain the negative effects of some but not all rumors. This explains why the Chinese government has recently decided to launch a legal and police campaign to crack down on internet rumors, while its previous handling of rumors had been relatively light-handed - it has acutely realized the insufficiency of rebuttals in battling rumors. ${ }^{103}$

One may wonder if the effects of the rumor treatments revealed in the experiments are of a short term nature and may not really matter in reality. It should be noted that the average effect

\footnotetext{
103 This is not to say that the Chinese government has no other motivations behind the campaign, which may well be used to silence all kinds of critical voices. But given the ubiquity of internet rumors in China and their negative effects for the government (as shown in this study), it is clear that rumors are indeed a critical target of the campaign.
} 
found in the experiments may actually be an underestimate of the real effects of rumors, given that the rumors in the experiments were from anonymous sources by construction (rather than from someone known to an internet user). Some of the experimental subjects had also seen some of the rumors before, while new and novel rumors may well have larger effects. Perhaps more importantly, Chinese internet users are often inundated with rumors in their routine online activities, ${ }^{104}$ as discussed earlier. Even though the influence of an individual rumor on citizens' political attitudes may or may not be enduring (that depends on the memorability of a particular rumor to a particular individual), the accumulated effects of experiencing such messages on a regular basis will be long lasting. The impact of rumors revealed in this article are therefore not confined to the experimental setting.

As the first explicit study of the political effects of rumors and rebuttals in an authoritarian country, this article has focused on routine rumors about various government wrongdoings that have emerged from the society. Future research can continue to investigate the effects of such rumors and their rebuttals, since the current article is just a first step in this line of research. Future studies, however, can also extend into other types of rumors, such as those about coups or political infighting, or rumors deliberately planted by the regime's opponents. Such rumors are also important elements of the informational dynamics in non-democracies, and studying them will yield a more complete picture of authoritarian information politics.

\section{REFERENCES}

Allport, Gordon W., and Leo Postman. 1947. The Psychology of Rumor. New York: Holt, Rinehart \& Winston.

Bauer, Raymond A., and David B. Gleicher. 1953. Word-of-Mouth Communication in the Soviet Union. Public Opinion Quarterly 17 (3):297-310.

Berinsky, Adam. 2012. Rumors, Truths, and Reality: A Study of Political Misinformation, working paper. Cambridge, MA: MIT.

Berinsky, Adam J., Geregory A. Huber, and Gabriel S. Lenz. 2012. Using Mechanical Turk as a Subject Recruitment Tool for Experimental Research. Political Analysis 20 (3):351-68.

Bilefsky, Dan. 2009. Celebrating Revolution With Roots in a Rumor. New York Times, 17 November.

Buhrmester, Michael, Tracy Kwang, and Samuel D. Gosling. 2011. Amazon's Mechanical Turk: A New Source of Inexpensive, Yet High-Quality, Data? Perspectives on Psychological Science $6(1): 3-5$.

Calvert, Randall L. 1985. The Value of Biased Information: A Rational Choice Model of Political Advice. Journal of Politics 47 (2):530-55.

Cao, Yin, and Baijie An. 2011. Weibo Gives Rumors No Time to Thrive. China Daily, 4 November. Available from http://www.chinadaily.com.cn/china/2011-11/04/content_14035335.htm (accessed 22 March 2013).

Chen, Jie. 2004. Popular Political Support in Urban China. Stanford, CA: Stanford University Press.

Chin, Josh, and Paul Mozur. 2013. China Intensifies Social-Media Crackdown. Wall Street Journal, 19 September.

Chong, Dennis, and James N. Druckman. 2007a. Framing Public Opinion in Competitive Democracies. American Political Science Review 101 (4):637-55.

—. 2007b. Framing Theory. Annual Review of Political Science 10:103-26.

- 2007c. A Theory of Framing and Opinion Formation in Competitive Elite Environments. Journal of Communication 57 (1):99-118.

CNNIC. 2015. The 35th Statistical Report of Internet Development in China (Zhong-guo Hulian Wangluo Fazhan Zhuangkuang Tongji Baogao). Beijing: China Internet Network Information Center.

104 Larson 2011; Yang et al. 2012. 
Cook, John, and Stephan Lewandowsky. 2011. The Debunking Handbook. St. Lucia, Australia: University of Queensland, Available from http://sks.to/debunk (accessed 22 March 2013).

DiFonzo, Nicholas, and Prashant Bordia. 2007. Rumor Psychology: Social and Organizational Approaches. Washington, DC: American Psychological Association.

Donovan, Pamela. 2007. How Idle is Idle Talk? One Hundred Years of Rumor Research. Diogenes 54 (1):59-82.

Druckman, James N. 2003. On the Limits of Framing Effects: Who Can Frame? Journal of Politics 63 (4):1041-66.

Druckman, James N., Erik Peterson, and Rune Slothuus. 2013. How Elite Partisan Polarization Affects Public Opinion Formation. American Political Science Review 107 (1):57-79.

Druckman, James N., and Toby Bolsen. 2011. Framing, Motivated Reasoning, and Opinions About Emergent Technologies. Journal of Communication 61 (4):659-88.

Ecker, Ullrich K.H., Stephan Lewandowsky, and David T.W. Tang. 2010. Explicit Warnings Reduce but Do Not Eliminate the Continued Influence of Misinformation. Memory \& Cognition 38 (8):1087-100.

The Economist. 2012. Twtr: Which Tongues Work Best for Microblogs? The Economist, 31 March. Available from http://www.economist.com/node/21551466 (accessed 22 March 2013).

Egorov, Georgy, Sergei Guriev, and Konstantin Sonin. 2009. Why Resource-Poor Dictators Allow Freer Media: A Theory and Evidence from Panel Data. American Political Science Review 103 (4): $645-68$.

Epstein, Gady. 2012. Online Whispers: The Anatomy of a Coup Rumour. The Economist, 5 April. Available from http://www.economist.com/blogs/analects/2012/04/online-whispers?fsrc=gn_ep (accessed 22 March 2013).

Fine, Gary A., and Bill Ellis. 2010. The Global Grapevine: Why Rumors of Terrorism, Immigration, and Trade Matter. New York: Oxford University Press.

Fine, Gary A., and Patricia A. Turner. 2001. Whispers on the Color Line: Rumor and Race in America. Berkeley and Los Angeles: University of California Press.

Garrett, R. Kelly. 2011. Troubling Consequences of Online Political Rumoring. Human Communication Research 37 (2):255-74.

Goodman, Joseph K., Cynthia E. Cryder, and Amar Cheema. 2012. Data Collection in a Flat World: Strengths and Weaknesses of Mechanical Turk Samples. Journal of Behavioral Decision Making 26 (3):213-24.

Goren, Paul, Christopher M. Federico, and Miki L. Kittilson. 2009. Source Cues, Partisan Identities, and Political Value Expression. American Journal of Political Science 53 (4):805-20.

Huang, Haifeng. Forthcoming. International Knowledge and Domestic Evaluations in a Changing Society: The Case of China. American Political Science Review.

2015. Propaganda as Signaling. Comparative Politics 47 (4):419-37.

Iyengar, Shanto. 2011. Laboratory Experiments in Political Science. In James N. Druckman, Donald P. Green, James H. Kuklinski and Authur Lupia (eds.) Cambridge Handbook of Experimental Political Science, 73-88. Cambridge University Press.

Ji, Chuanpai, and Hao Wang. 2011. Beijing Party Secretary Visits Sina and Stresses the Strengthening of New Technology Applications. Beijing Daily, 23 August. Available from http://news.sina.com.cn/c/ 2011-08-23/032523033585.shtml (accessed 22 March 2013).

Johnson, Hohhyn M., and Collen M. Seifert. 1994. Sources of the Continued Influence Effect: When Misinformation in Memory Affects Later Inferences. Journal of Experimental Psychology: Learning, Memory, and Cognition 20 (6):1420-36.

Kapferer, Jean-Noel. 1990. Rumors: Uses, Interpretations, and Images. New Brunswick: Transaction Publishers.

Kenez, Peter. 1985. The Birth of the Propaganda State: Soviet Methods of Mass Mobilization, 1917-1929. Cambridge: Cambridge University Press.

King, Gary, Jennifer Pan, and Margaret E. Roberts. 2013. How Censorship in China Allows Government Criticism but Silences Collective Expression. American Political Science Review 107 (2):326-43. 
- 2014. Reverse-Engineering Censorship in China: Randomized Experimentation and Participant Observation. Science 345 (6199):1-10.

Knopf, Terry A. 1975. Rumors, Race, and Riots. New Brunswick: Transaction Books.

Koller, Michael. 1992. Rumor Rebuttal in the Marketplace. Journal of Economic Psychology 13 (1):167-86.

Kuklinski, James H., and Norman Hurley. 1994. On Hearing and Interpreting Political Messages: A Cautionary Tale of Citizen Cue-Taking. Journal of Politics 56 (3):729-51.

Larson, Christina. 2011. People's Republic of Rumors. Foreign Policy, 8 July. Available from http://www. foreignpolicy.com/articles/2011/07/08/the_peoples_republic_of_rumors (accessed 22 March 2013). 2012. Still the Peoples Republic of Rumors. Foreign Policy, 22 March. Available from http://blog. foreignpolicy.com/posts/2012/03/22/still_the_people_s_republic_of_rumors (accessed 22 March 2013).

Levin, Dan. 2014. China Cracks Down on Popular Mobile Messaging Services. New York Times, 7 August.

Li, Lianjiang. 2013. The Magnitude and Resilience of Trust in the Center. Modern China 39 (1):3-36.

Lorentzen, Peter L. 2014. China's Strategic Censorship. American Journal of Political Science 58 (2): 402-14.

Lupia, Arthur. 1994. Shortcuts Versus Encyclopedias: Information and Voting Behavior in California Insurance Reform Elections. American Political Science Review 88 (1):63-76.

MacKinnon, Mark. 2012. Why the Coup Rumours in China Aren't Going Away. The Globe and Mail, 21 March.

Mayo, Ruth, Yaacov Schul, and Eugene Burnstein. 2004. I Am Not Guilty Vs. I Am Innocent: Successful Negation May Depend on the Schema Used for Its Encoding. Journal of Experimental Social Psychology 40 (4):433-49.

Mocanu, Delia, Luca Rossi, Qian Zhang, Marton Karsai, and Walter Quattrociocchi. 2014. Collective Attention in the Age of (Mis)Information, arXiv:1403.3344 [cs.SI].

Mondak, Jeffrey J. 1993. Source Cues and Policy Approval: The Cognitive Dynamics of Public Support for the Reagan Agenda. American Journal of Political Science 37 (1):186-212.

Ng, Jason Q. 2013. Blocked on Weibo: What Gets Suppressed on Chinas Version of Twitter (and Why). New York: The New Press.

Nicholson, Stephen P. 2011. Dominating Cues and the Limits of Elite Influence. Journal of Politics 73 (4):1165-77.

- 2012. Polarizing Cues. American Journal of Political Science 56 (1):52-66.

Nicholson, Stephen P., and Thomas G. Hansford. 2014. Partisans in Robes: Party Cues and Public Acceptance of Supreme Court Decisions. American Journal of Political Science 58 (3): 620-636.

Nyhan, Brendan, and Jason Reifler. 2010. When Corrections Fail: The Persistence of Political Misperceptions. Political Behavior 32:303-30.

2012. Misinformation and Fact-Checking: Research Findings from Social Science. Washington, DC: New America Foundation, New America Foundation.

- forthcoming. The Effect of Fact-Checking on Elites: A Field Experiment on U.S. State Legislators. American Journal of Political Science.

O'Keefe, Daniel J. 2002. Persuasion: Theory and Research. $2^{\text {nd }}$ edition. Thousand Oaks, CA: Sage Publications.

Oliver, J. Eric, and Thomas J. Wood. 2014. Conspiracy Theories and the Paranoid Style(s) of Mass Opinion. American Journal of Political Science 58 (4):952-66.

Pei, Minxin. 2008. Rumors and Riots. New York Times, 8 July.

People's Daily Online Media Opinion Monitoring Office. 2012. 2012 Sina Government Weibos Report. Beijing: People's Daily Online Media Opinion Monitoring Office.

Richburg, Keith B. 2011. In China, Microblogging Sites Become Free-Speech Platform. Washington Post, 27 March.

Ross, Lee, Mark R. Lepper, and Michael Hubbard. 1975. Perseverance in Self-Perception and Social Perception: Biased Attributional Processes in the Debriefing Paradigm. Journal of Personality and Social Psychology 32 (5):880-92. 
Schwarz, Norbert, Lawrence J. Sanna, Ian Skurnik, and Carolyn Yoon. 2007. Metacognitive Experiences and the Intricacies of Setting People Straight: Implications for Debiasing and Public Information Campaigns. Advances in Experimental Social Psychology 39:127-61.

Shi, Tianjian. 2001. Cultural Values and Political Trust: A Comparison of the People's Republic of China and Taiwan. Comparative Politics 33 (4):401-19.

Shirk, Susan L., ed 2010. Changing Media, Changing China. New York: Oxford University Press.

Sniderman, Paul M., and Sean M. Theriault. 2004. The Structure of Political Argument and the Logic of Issue Framing. In Studies in Public Opinion: Attitudes, Nonattitudes, Measurement Error, and Change, Chapter 5, edited by Willem E. Saris and Paul M. Sniderman, 133-65. Princeton, NJ: Princeton University Press.

Sprouse, Jon. 2011. A Validation of Amazon Mechanical Turk for the Collection of Acceptability Judgments in Linguistic Theory. Behavior Research Methods 43 (1):155-67.

Stockmann, Daniela. 2013. Media Commercialization and Authoritarian Rule in China. New York: Cambridge University Press.

Tong, Yanqi, and Shaohua Lei. 2013. War of Position and Microblogging in China. Journal of Contemporary China 22 (80):292-311.

Uscinski, Joseph E., and Joseph M. Parent. 2014. American Conspiracy Theories. New York: Oxford University Press.

Wedeen, Lisa. 1999. Ambiguities of Domination: Politics, Rhetoric, and Symbols in Contemporary Syria. Chicago, IL and London: University of Chicago Press.

Weeks, Brian E., and R. Kelly Garrett. 2014. Electoral Consequences of Political Rumors: Motivated Reasoning, Candidate Rumors, and Vote Choice During the 2008 US Presidential Election. International Journal of Public Opinion Research 26 (4):401-22.

Wines, Michael. 2012. Crackdown on Chinese Bloggers Who Fight the Censors with Puns. New York Times, 28 May.

Xinhua News Agency. 2012. A Few Rumor-Spreading Web Sites Punished According to Law (Yipi Chuanbo Yaoyan De Wulian Wangzhan Bei Yifa Chengchu). Available from http://news.xinhuanet. com/politics/2012-03/30/c_122911337.htm (accessed 30 March 2013).

Yang, Fan, Yang Liu, Xiaohui Yu, and Mim Yang. 2012. Automatic Detection of Rumor on Sina Weibo. Proceedings of the ACM SIGKDD Workshop on Mining Data Semantics. Beijing, 12-16 August 2012.

Yang, Guobin. 2013. Contesting Food Safety in the Chinese Media: Between Hegemony and Counter-Hegemony. China Quarterly 214:337-55.

Yu, Louis, Sitaram Asur, and Bernardo A. Huberman. 2011. What Trends in Chinese Social Media. Proceeding of the 5th ACM Workshop on Social Network Mining and Analysis (SNAKDD2011), 21 August 2011, San Diego, CA.

Zaller, John. 1992. The Nature and Origins of Mass Opinion. New York: Cambridge University Press.

Zhao, Dingxin. 2001. The Power of Tiananmen: State-Society Relations and the 1989 Beijing Student Movement. Chicago, IL and London: University of Chicago Press.

Zhong, Yang. 2014. Do Chinese People Trust Their Local Government, and Why? An Empirical Study of Political Trust in Urban China. Problems of Post-Socialism 61 (3):31-44.

Zhu, Jiangnan, Jie Lu, and Tianjian Shi. 2013. When Grapevine News Meets Mass Media: Different Information Sources and Popular Perceptions of Government Corruption in Mainland China. Comparative Political Studies 46 (8):920-46. 